Grigor DOYTCHINOV

\section{Sofia - A city of potentials, a city in a discontinuum}

\section{Introduction}

Sofia is situated in a valley basin, $550-700 \mathrm{~m}$ above sea level, and covers an area of $1342 \mathrm{~km}^{2}$. The city is steeped in history and is the cultural centre of the country. Sofia owes its reputation of being a "green city « to its spacious parks and gardens. The dominant mountain scape framing the city and the cultural heritage make the city a centre of national and international interest. The city's motto is "grows but does not age «. The municipality of Sofia comprises thirty-eight towns and villages with a total population of $1,174,000$ inhabitants, with $1,096,000$ in the city of Sofia. Socially, economically and in terms of infrastructure, Sofia is the best developed municipality in the country. This statement is backed up by the following statistics: in 2000, the city achieved $24.6 \%$ of the country's GNP (with $15.2 \%$ of total inhabitants); the tertiary sector leads the field with a percentage of $66.6 \%$, providing $71.3 \%$ of jobs; the capital city function is an important factor for this key sector; nineteen of the forty-two universities and forty-two per cent of all students are concentrated in Sofia, and it is the country's biggest research centre; in 2001, the city numbered twentythree theatres, twenty-nine museums, thirty-one cinemas, and 116 public libraries. Sofia is located at the centre of transeuropean transport corridors No. 10 (Belgrade - Sofia - Istanbul), No. 4 (Budapest - Vidin - Sofia Thessaloniki), and No. 8 (Dürres - Skopje - Sofia - Burgas and Varna). This is a prerequisite for establishing the city as a central location in the region of south-east Europe.[1]

\section{A city in planning - wishes and reality}

European urbanisation did not take hold of Sofia until after restitution of national independence in 1878. Until then, the physical make-up of the 17,000-inhabitant city had been characterised by the "mahala «, the relatively autonomous settlement unit that is formed around ethnicity and family relationship. Not until the turn of the nineteenth century did the city undergo a metamorphosis, with social life, once restricted to the "Mahala«, moving out onto the streets in search of public expression. ${ }^{[2]}$

With Bulgaria's reborn in 1878, people began to recognise the importance of the cities for the development of the national middle-class spirit, making the redevelopment of Sofia into the country's capital a matter of national intellectual prestige. In the period between 1878 and 1918 we observe two periods of development in Sofia. The first is a period of total reorganisation of the city that impacted on the entire inhabited area from the Ottoman age. The second, from 1897 to World War I, is characterised by systematic expansion. The process of designing the capital city was for the most part completed by World War I. Sofia quickly ceased to be an underdeveloped, Oriental city and became a European metropolis.[3]

This systematic beginning suffered a setback as a result of the demographic crisis in the wake of World War I caused by the unprecedented wave of migration from Macedonia, Thrace, Dobrudsha and Morava. The city is practically surrounded by slums that spring up on undeveloped territory. Although the local authorities are now belatedly regulating some of these territories, they are hardly able to get the situation under control. The nineteen-thirties were characterised by the optimism of economic upturn. But economic growth entailed a building boom and another - as yet unk-

Table 1: Rank of importance of selected European capitals and cities

\begin{tabular}{|l|l|l|}
\hline \multicolumn{1}{|c|}{ City } & \multicolumn{2}{c|}{ Until $\mathbf{2 0 0 0}$} \\
\hline Tirana & with national functions & with national functions \\
\hline Vienna & of European importance & of European importance \\
\hline Sarajevo & with regional functions & with national functions \\
\hline Sofia & with national functions & of European importance \\
\hline Zagreb & with national functions & with national functions \\
\hline Prague & with national functions & of European importance \\
\hline Berlin & with national functions & of international importance \\
\hline Budapest & with national functions & of European importance \\
\hline Rome & of international importance & of international importance \\
\hline Skopje & with regional functions & with national functions \\
\hline Warsaw & with national functions & of international importance \\
\hline Bucurest & with national functions & of international importance \\
\hline Bratislava & with national functions & with national functions \\
\hline Ljubljana & with national functions & with national functions \\
\hline Odessa & with national functions & with national functions \\
\hline Paris & of international importance & of international importance \\
\hline London & of international importance & of international importance \\
\hline
\end{tabular}

Source: Vision Planet, Report of the European Commission: Perspectives and strategies of spatial development of Central European countries, countries of the Danube and Adriatic regions, Bonn, 1998. 
nown - reorganisation of the city primarily characterised by housing construction, a development that the city did not get under control until between 1934 and 1938. In terms of planning, these are among the most fertile, most active years in the history of planning in the city. Efforts to organise the city's make-up led to a plan in 1938 that took the form of a development strategy and exhibits the main features of modern urban planning. ${ }^{[4]}$

The critical state of the city in the years after World War II was due to the rapid changes in the country's social and political system. The destruction of a substantial amount of residential buildings (approx. 12.000) by bombing in World War II, the growing pressure of migration arising due to large-scale collectivization in the farming industry, and the onset of industrialization in the city were all factors that considerably hampered efforts to control the urban space. In order to get to grips with the situation, the authorities began initial planning efforts; due to a lack of investments or reinvestment in other branches of industry, however, these all gradually passed into oblivion. The plan approved in 1961 very soon fell behind the great rate of escalating urban growth. Just five or six years after the plan was approved, forecasts that put planned growth at 800,000 inhabitants were already outdated. There were already suitable conditions for starting a new plan in 1969. Subsequent urban development studies and planning efforts from 1972-1979 were replete with ideas and radical visions for the future. However, they soon turned out to be too avant-garde and theoretical. The political leaders of the city and the country judged them to be "unrealistic « in view of the excessively high demographic and territorial growth forecasts on which the plans were based.

A new plan was submitted for review in 1979 and approved by the local authorities and the government. Despite this acceptance, the plan was thwarted by the necessary agreement with the leaders of the governing $\mathrm{CP}$, who did not approve the plan. Instead, and in contradiction to statements made in the plan, the national government decided to develop new, unused territories on the edge of the city for housing development. The plan was updated in 1985 on the basis of this government resolution without correcting its content or taking steps to make it legally valid.[5]

Once again, it was a political and territorial watershed after 1989 that created a totally new situation. The collapse of the socialist system greatly diminished the influence of the public authorities on urban developers. This change also marked the start of a new phase in urban planning in Sofia. In these new conditions it was not longer possible to organise the city with the aid of the usual instruments, and a new critical situation evolved.

After 1989, due to the political boom, the concept of »new urban planning « made a brief appearance and initially gained a fairly firm foothold. It is unfortunate that representatives of this profession pay court to the mass media, who, in turn, provide unprofessional support. This promoted a false myth of the changes. Is there really a change in urban planning in Sofia? New questions of urban development are indeed being answered. Every change adds new problems and gives rise to new questions. On this basis, we can probably rather speak of a reorientation of urban planning and adaptation to the new kinds of problems. In this sense, the new feature in urban planning is the change of attitude.[6]
Hence, the procedures employed in the zoning plan approved in 2004 cannot be regarded as »new « or »original «. Although tried-and-tested methods and instruments are employed, the objectives are more realistic and the planning statements are formulated with greater flexibility. Expectations have clearly dropped regarding the beacon function of urban planning. There are no new methods, but some new principles have slowly gained a foothold in the public awareness. The landmark realisation is that the development of the city cannot be founded on the idea of physically balanced quality. The change of paradigm has also cast off the radical motto of "either/or «. A fundamental change in this context is the decision to stop searching for universally applicable rules and to look for specific factors instead.

In retrospect, despite the discontinuous development of the city, we can still derive a few urban planning laws and patterns. The above-mentioned plans are intended to be models for physical planning and urban development. Practical implementation of the plans was not thwarted due to a lack of forecasts or visions, or by the failure to achieve the planning horizon, but rather due to the emergence of unforeseen crises that rendered the contents of the plans outdated and thus made it impossible to put the plans into practice. We can observe a distinct sequence:

- Every period of applying the plan is interrupted by the appearance of an unforeseen crisis.

- The outdated planning parameters are hurriedly replaced by unsystematic first-aid efforts by the local authorities. There follows a period in which the lack of a valid plan is seen by the local authorities as a convenience for taking short-term decisions. Individual ideas from the dropped plan are applied only selectively and without context.

- Naturally enough, this haphazard development leads to an aggravation of the problems in the city, thus promoting public awareness for the necessity of a new plan.

The general conclusion is that planning efforts for Sofia, conceived as models for urban development, do not appear in a continuous, logical sequence, but are rather due to the effect of successive, destructive breaks and crises.

\section{Mono-centrism of the urban structure as an unresolved problem}

In the 120-year period of urban development, the city's planning structure has evolved according to a radial pattern. Today, it exhibits a compact centristic structure with radial compact extensions. It already displayed this development around 1900 and has retained this character to date, despite the rapid demographic and territorial development. The system of spacious urban parks and gardens forms the structuring radial elements in the concentric system. The physical structure of the city exhibits four distinct concentric zones that each expresses the different stages of development, mode of construction, and natural conditions:

- the city centre,

- the belt around the city centre, defining the zone of the historic centre;

- the peripheral zone, characterised by the post-war housing complexes that define the physical make-up of the compact city, and

- the amorphous zone outside the compact city, consisting of small villages and villa districts. 
In terms of its building land boundaries, Sofia is a particularly compact city with a high population density compared to western European cities (56 inhabitants/ha). This density is highest in the city centre, decreasing in the second historic centre zone, and rapidly rising again in the peripheral zone with its post-war housing complexes. The density drops abruptly outside the compact city. The difference in density between the peripheral zone and the zone outside the compact city has a great influence in terms of urban design. However, building activity has increased in this outer zone in the last decade. This activity is focused primarily on the south of the city, in the transition zone to the attractive Vitosha Mountain.

Despite the planning intentions for a polycentric system, the city displays a distinctly monocentric structure. No sub-centres were able to establish themselves until 1989, for whatever reasons. Following the political turnaround, the territories reserved for sub-centres in the plans were the first victims of commercial housing construction and were heavily developed. As a result, the territories that could have been used to establish sub-centres were lost as potential land.

At the same time, problems are beginning to increase in the city centre that hampers effective performance of key functions. The general condition of the buildings and infrastructure in the historic parts of the city are continuing to decline. Important public sites are degenerating into inhuman traffic areas. The supply of office premises in the centre is regarded as insufficient, although no new office and business centres are being built. This demand is leading to an arbitrary spread of office buildings and company headquarters throughout the entire city. One very disturbing problem in the city centre is the lack of parking facilities and car parks and the resultant traffic chaos. In addition, the strongly radial layout of the roadways burdens the city centre with through traffic and does nothing to stimulate the emergence of sub-centres in other areas of the city. In reality, there are no primary or secondary bypasses to draw the traffic away from the centre. At the same time, however, more and more new office and commercial buildings have been built along the radial roads over the past decade. Although this trend is positive, it is no substitute for the need for sub-centres.

The border areas of the compact city have a great potential of territories zoned for commercial use. For the most part, they were set up in the period of socialist planning, when industry was a high-priority sector, developing extensively and consuming vast amounts of resources - including land. With today's prevalent processes of market reforms and structural change, the percentage of land zoned for commercial and industrial use ( $27 \%$ of building land) no longer correlates with the logic of economic considerations and physical planning. On top of that, $34 \%$ of this land is located within a radius of just $4 \mathrm{~km}$ from the city centre. With regard to the declining number of people working in industry, it is necessary to focus, reconstruct or relocate commercial enterprises.

There is a serious imbalance between the quality of life and the intensity of land use between the north and the south of the city, divided by the railway site and the associated traffic areas and warehouse facilities. The north exhibits inferior parameters in terms of ecology, sanitary hygiene, and traffic, which is reflected in the real estate market: investment activity and real estate prices are far lower in the north than in the south. The large number of derelict industrial sites in the north, which would require substantial funds to renovate for new uses, is further factor that repel investors. Implementation of the European traffic corridors routes 4,8 and 10, that are to be linked up on the north edge of the compact city, could alleviate this imbalance.

The vast land resources outside the compact city should not be underestimated; these areas could accommodate many urban functions and activities without disrupting the territorial balance of the city. The extensively developed localities in this outside zone could also accommodate additional functions for all areas of life without the need for expansion. The crisis in the economic development of these areas and the small potential of inhabitants has uncovered additional land reserves for development. There is a particularly large potential of high-quality areas for leisure facilities in the mountain areas nearby the city that are very characteristic of Sofia's image. Not to forget, the city has already applied to host the Winter Olympics twice with considerable success.

\section{Conclusion - conditions and factors for urban development}

The future development of the city is influenced by a number of factors and underlying conditions that can slow down or accelerate these processes quite considerably. First and foremost, these are geopolitical and geographical factors due to the strategic location of the city in the region of south-east Europe. The remoteness of the city from the densely populated areas of western Europe is without a doubt a negative factor of influence, for it prevents an active flow of innovations, commodities and individuals that are important in order to integrate the city in the European economic zone and network of cities. This distance does not provide good conditions for locating business activities, based upon western European capitals and technologies, and is one of the causes of the relatively low investment rate in Bulgaria.

The fundamental political factor that will impact positively on the development of Sofia is the process of accepting the country into the EU. Integration of the country into Europe is the result not only of formal fulfilment of the conditions of membership, but also of a number of regional processes in the Balkans. Once conditions had stabilised in the neighbouring successor states of Yugoslavia, the process of integration took on a new dimension that is geared to intensifying regional integration. With regard to the dependence of Bulgaria and the capital city Sofia on foreign investments, this regional integration is of major importance. Once the country joins the EU in 2007, it will be able to take advantage of European funds just in time and at a higher level. This will stimulate regional development and investments in the country and increase traffic links to Romania and Greece. Although the funds for regional development will be limited for Sofia, infrastructural networking is a tremendous stimulator for the city.

Another set of very important conditions concern the positioning of the city in the global market and in east and south-east Europe. Current trends give cause to expect that Sofia has considerable opportunities for development and 
growth. These are due primarily to the geostrategic location of the city. An interesting aspect for western Europe is that it will be possible to transfer west European capital across the Balkan Peninsula and Bulgaria to eastern Europe, the Near East, and Central Asia. The East, in turn, is interested in placing its products on western European markets. From this point of view, Sofia is a very important location. For the Balkan region, as a new promising European region, in which the formation of a stable network of central locations has yet to be completed, the cities of Sofia, Bucharest, Belgrade, Skopje, Tirana, Thessaloniki, Varna and Constanta are vying for a significant regional and continental status. It is obvious that the capital Sofia will only have a real chance to attract investments in the competition with the other major cities of south-east Europe if it can take advantage of its strategic position by means of its policies and by steering its processes - a position at a junction of European corridors and the central location in the dynamically changing Balkan region.

The demographic features of the city provide a certain edge in the competition with other major cities in southeast Europe. With its material base, qualified experts and traditions in certain branches of research and production, the city can establish itself as a specific technology bridge between the West and the East. The meanwhile well developed tertiary sector offers many niches for this transfer. The city's universities and research facilities can become bases. The orientation of capital to cities with qualified personnel and quality of life gives Sofia unique opportunities in the region and in the European context, as the level of education of the city's inhabitants are very good. The large percentage of economically active individuals with university or college education (66\%) is an important prerequisite for attracting high-tech production. In this context it is interesting to refer to the »Vision Planet « study in order to review western European assessments of the Sofia's potentials. The EU Commission's report on »The perspectives and strategies for physical development of the countries in Central Europe, the Danube region and the Adriatic «, written in 1998, emphasises the continental importance of the city in the future.

Last but not least, national conditions and factors open up perspectives for the city. In the entire period of being capital city, Sofia has always been the location with the most dynamic development in the country. This fact has an economic, political and social explanation. The extremely important influence of the city on the country's economic growth is the reason why the regional planning act defines it as a "growth area «.

It is not possible to list the whole bandwidth of factors influencing the city without mentioning the natural restrictions and stimuli that are of such great importance for Sofia. The city's outstanding natural setting has a contradictory influence on the development of the city. The mountains surrounding the Sofia field, particularly Vitoscha Mountain, with its highest point at $2225 \mathrm{~m}$, are part of the city's image and a key natural factor for the quality of life. The skiing resorts on Vitosha Mountain and on the nearby Rila Mountain were already popular international tourist destinations prior to 1989 and are the main argument behind the city's applications to host the Winter Olympics. These skiing resorts, about an hour away from the city, have enjoyed a veritable boom of tourism, visitors and new hotel buildings over the past decade. Plans to extend the skiing resorts are already being elaborated. A second plan focuses on the topography (hills) in the compact city, that serve as panorama sites and visual landmarks, particularly the area of the historic centre. The city's mineral springs, which were also originally factors for founding the city, hold special potential. They are only partially in use.

Grigor Doytchinov, Univ. Prof. Dr. techn. arch., University of Technology Graz

E-mail: doychinov@stdb.tu-graz.ac.at

\section{Notes}

[1] Sofia. 120 Years as Capital of Bulgaria, 2002.

[2] Doychinov, Ganchev, 2001.

[3] Doychinov, 1989.

[4] Doychinov, Ganchev, 1989.

[5] Sofia Master Plan, 2002

[6] Doychinov, 2002.

\section{Illustrations}

Figure 1: View of Mount Vitosha, the most important landmark of the Sofia region. Photo: Grigor Doytchinov.

Figure 2: Distances between Sofia and the capitals in southeastern Europe. Source: Sofia. 120 Years as capital of Bulgaria, Sofia 2002.

Figure 3: The City of Sofia on the background of the European transport corridor network. Source: Sofia Master Plan 2004.

Figure 4: Spatial structure of the region showing the frame of mountains surrounding the field of Sofia. Source: Sofia Master Plan 2004.

Figure 5: Tendencies in the developmant of the central functions. Source: Sofia Master Plan 2004.

Figure 6: Directions of long terme space development. Source: Sofia Master Plan 2004.

For sources and literature turn to page 31. 